\title{
Research on Application of National Elements in Animation Design
}

\author{
Saihua Xu \\ School of Information, Nanchang Institute of science \& Technology, Nanchang, 330108, China \\ xusaihuapaper@163.com
}

Keywords: National Element; Animation Design; Animation; Feature.

\begin{abstract}
Combining national culture with the animation design, integrating especial national cultural elements of Chinese into the animation design, which not only can makes rural animation design more diversified, but also effectively spread the fine spirit and culture of nation through the world. How to incorporate national elements for a Chinese animation designer is very interesting in animation design work, which can improve the international competitiveness of animation design works. This paper analyzes the Chinese elements of Chinese animation, and then discusses the current situation, the existing problems and some corresponding improvement methods.
\end{abstract}

\section{Introduction}

Under the background of economic globalization, international borders have less important, even in different countries, we can see the same work. Especially with the multinational development of animation, whatever part of the world they come from, all recognize Mickey Mouse and Donald Duck. A good animation works can not only gives children pleasure, but only let the children learn knowledge. Integrating the national elements into animation design, which can integrate national history and culture into animation works, so as to let children grasp national history culture. The creative course of animation can broaden because of its integrating into national elements, which enriches animation content [1-2]. In addition, it can not only bring inspiration to animation creation, but also promote the national culture. Therefore, it is fully staffed that combination animation design and national elements.

\section{The Current situation of the Chinese Animation Design}

In the first of the 20th century, there were many good animations in china. A lot of people were deeply impressed by these animation works, such as "Making havoc in Heaven", "Calabash Brothers" and "Little Tadpole Looking for Mummy", etc. Every story of these animations were lively and interesting, they have become classic works of the Times. The china's animation has also made proud achievements in the world. Nowadays, the market of Chinese animation has been accounted for nearly half of the market by foreign animation. Chinese animations are described as without fun works[3-4]. What is the cause of this? Japanese animations were output from Japan to china with pay in the late 80s. Children were not impressed with "Transformers" at that time. However, in the years since then, Chinese animation technology resumed their descent, and most of animations are short of narrative and appeal. This was partly due to blindly following their mentality, which lose national culture.

There are some problems in Chinese animation design, such as single characters, simple and boring story lines, so that it can not produce understanding and inspired thinking. How to change the status of Chinese animation? This is not to say that the Chinese animation can change form, but it is a road of Chinese animation to development. We can not use national elements to enrich content of Chinese animation and embody cultural connotation of Chinese animations, but also can add national elements to Chinese animation and spread Chinese culture around the world. 


\section{The effect of the National Elements in Animation Design}

Animation creation actually implies the interpretation of culture inheritance and transmission of every nation. By analyzing and studying many successful animation works, we can find that their success depend on absorbing every nation culture. These successful animation works can find the subject of animation creation from different national culture and innovate them based on the native nation culture. In a word, animation creation is in fact cultural transmission to bridge the gap between different countries[5]. Many excellent animation designers can experience different cultures of other countries, and summarize the essence of national culture in accordance with the native nation culture. Finally they will bring excellent culture of other nation to animation creation. These works can have vitality and attract eyeballs. Owing to combining advanced technology from foreign countries with historical theme, some excellent animation works had been created.

Look back the development of animation, during the long road of animation creation, the Chinese animation experiences processes from borrowing foreign advanced technology and historical experience to create animation with the native nation character. During this procedure, Chinese animation technology maintained a good development direction and strong life. It is very vital to use the national elements to create animation works [6]. For animation designer, who must be able to learn every national culture, and apply the traditional cultures of Chinese nation in animation creation?

\section{The effect of the National Elements in Animation Design}

\subsection{The Application of the National Elements in Original Animation Work}

From the animation development point of view, American and Japanese animation has developed at a comparatively great speed, but Chinese animation show the echo-phenomenon. However, it is a road to lose our self and self-destruction. Because the imitation will never bring progress, only integrating the native nation culture with animation design, which can save the current situation of Chinese animation. "Making havoc in Heaven" was a successful works in the past, it is also a successful animation work today. It embodies Chinese traditional art style, which has not only aesthetic sense of arts, but also features of Chinese culture. The works combines Occidental watercolor painting and gouache. More importantly, it has strong Chinese characteristics.

\subsection{The Application of the National Elements in Animation Characters Creation}

Animation is artistic and commercial works, whether animation works is successful or not is welcomed by public. Animation character is one of the most elements in animation creation, which is it is the key to the success or failure. Sun Wu Kong is a soul in the animation "Making havoc in Heaven". A complete animation need to consider its story background, the characters of the historical background and role characteristics, etc. Taking "Making havoc in Heaven" as an example, the works uses clothing characteristic of China's Peking Opera to shape figure image. The exaggerated clothing characteristics and image were applied in shaping of figure image, and the works is with distinctive Chinese national features. Taking other animation works "Konfu Panda" as an example, "panda" and other animals of the works all have strong Chinese feature. Especially, the elements of the Chinese kung fu the animation were introduced to the animation works, which reflects the Chinese culture characteristics. So, the success of animation design is closely related to the role of design, and the design of the role is also closely related to national elements. It is one of the secret of success that national elements were ingeniously applied in shaping of animation role.

\subsection{The Application of the National Elements in Animation Scene Creation}

In addition, animation scene design is also an important part in animation design. The animation designer can design scene in accordance with specific historical and cultural background, and integrate animation roles into animation scene, which can deepen national impression. Integrating the ancient murals, construction and other ethnic elements with scene design, and strengthen decorative features of animation scene with innovative ways, which makes scene and roles achieve the role of good cooperation. The animation works "Konfu Panda" use landscape to design scene, which make 
the landscape scene show a Chinese calligraphy art, a kind of Oriental verve and special feelings, and embodies the unique charm of Chinese nation elements.

\section{The effect of the National Elements in Animation Design}

The writer think to above standpoint after making synthesize the analysis, there have some following notes.

\subsection{The characters designs should be awarded to strong personality.}

The leading role of the Chinese animation must be brave and justice, such as Sun Wukong, tablets and the gourd WA, which they are not as "much A dream", "Panda" of "Kung Fu Panda". The leading role of the Chinese animation must be the man of god or the hero in the model operas. As a result, it will lose their individuality.

The appearance is primary in the design of role and scene. The feelings of the Chinese people are more introverted and prefer to endow role and scene. Actually, it is very important for ordinary people, but how many people could understand real meaning? Firstly, a role appearance of loveliness and individuality can arouse one's feelings. Secondly, the role should be endowed to characters' sharp personalities. The personality is soul bring the roles to life.

\subsection{The Original is the Vitality of Animation Works}

China is a very big processing country, the $70 \%$ of Japanese animations were made in China, such as "Saint Seiya" and "Rurouni Kenshin", etc. These animation works were all made in China. In fact, we are not short of design talents, but short of creative talents.

The 4th China International Comic and Game Expo come to an end, which was sponsored and undertaken by the Ministry of Culture of China and the Shanghai government. Mr Wu Guanying of Tsting Hua University, the China Academy of Art also took part in the China International Comic and Game Expo, who said that the abundant cultural deposits can bring creative idea to animation creation, however, these chances had been grabbed by overseas enterprises because we were short of creative talents. We often focused on the order processing, ignores the originality. The original animation works is the vitality of animation industry. The animation enterprise should start from originality and do the market well, which can form a brand. Good creation and system play an indispensable role on animation creation and the two are supplementary.

\subsection{Unreal feeling Of National Culture weakens the Cultural product.}

As the saying goes, the more national, the more of the world. The problem of Chinese animation development had been talked about by animation experts. Though the works came from Chinese elements, why did not it keep pace with overseas same profession? These problems increase gradually with the releasing of "kung fu panda". How to introduce these Chinese elements to animation design is one of the key. It is very not easy that the works can reflect the traditional Chinese culture and be accepted by young people, accepted by the world. Many people today are unfamiliar to Chinese tradition culture. Chinese culture is profound, which is rich cultural background. It can provide creative ideas for animation. Finding out the coherence point of traditional culture and anime, and explore the era characteristics, which will become a key national element anime.

\subsection{Attitude decides everything, detail makes difference}

The "Kung Fu Panda" of animation had been made for the past five years, during the five years, they had came here himself to experience Chinese culture, such as Lijiang, Guilin, etc. And they had also watched a lot of Hong Kong and China s martial arts films, etc. Hollywood filmmakers have rigorous attitude and scientific method.The saying goes that "Attitude decides everything, detail makes difference". Therefore, we should learn from Hollywood directors, who haves a big rigorous attitude.

\subsection{Animation Works should accord with international norms.}

Hollywood's work material stems from the various countries' culture. The "Mermaids" and "for the little match girl" from Danish were adapted from Andersen's tales. The "Romeo and Juliet" and "Hamlet" were adapted from Shakespeare. The reason that these animations can have a great success, 
is mainly because they were introduced cultural connotations of these countries in animation creation. Taking "Kung Fu Panda" for example, the animation shows that it contains the Chinese kung fu and different region amorous feelings, which contains theme of "courage and responsibility". The feeling and seeking has universal values. According to the ideological basis, the animation works can arouse people of different countries, culture, ages and hierarchy feelings. These cultures of animation were integrated into the world more and more, to say the least.

Secondly, the "kung fu panda" is run on the international cinemas and international box office and lines, which also includes Chinese market. Under this new background, the creative form has played more and more important role in national economy's development. The Many methods of them are worth studying and learning. South Korea promotes enterprises to produce cultural content of products through act of government, and sets up specialized agencies "Korean culture revitalization of the school", and in a short period of time, the trade deficit was turned into trade deficit. Japan is a big animation exporter. Japanese diplomats have decided to engage in "diplomacy".

In view of this, we should straighten out the system of culture, break not frameworks of impeding production, marketing and propagation of animation products, which can allocate rationally the cultural resource, optimize the allocation pattern. One day, our animation product can bring light like a Hollywood star, we have reason to believe that everyone will concern Chinese animation.

\section{Summary}

At present, Chinese animation is in the transitional period of instability, it is a good choice for animation designer to combine the national elements with animation design, and there is significant possibility that they would succeed. In addition, China has a rich history and a profound traditional culture, which could provide broad space and space for her animation creation. The animation creation should try to make the most of advantage of Chinese nation culture and create the original animation works, which not only benefits development of Chinese animation, but also benefits the propagation of Chinese national culture.

\section{References}

[1]. RONG L. Excavating Folk Art Element and Build Animation Art Brand. China Collective Economy, Vol. 9 (2011) No.20:71-72.

[2]. ZHANG H H. Feeling on Image Design Creation of Modern Animation. Cultural Information, Vol.11 (2011) No.10:17-18.

[3]. ZHANG R R and WANG L. Movie Review, Discussing on Application of Traditional Elements in Animation Costumes Design. Vol. 9 (2010) No.10:33-34.

[4]. LIU Y. Kung Fu Panda- Spread of the Chinese Culture and Chinese Elements. Media, Vol. 9 (2010) No.3:25-26.

[5]. ZHANG B. "Export" and "Import" is "Kung fu" Confusion of Chinese Cultural Elements, China Business Daily, Vol. 7 (2008) No.4: 15-16.

[6]. LIU S Y. Talking on Application of Chinese Elements in Animation Design .On the Innovation Design of Chinese Traditional Pattern, Journal of Hubei Institute of Economic (Social Sciences), Vol. 27 (2009) No.10: 37-38. 